Technical Note

\title{
Thermal Conductivity of Korean Compacted Bentonite Buffer Materials for a Nuclear Waste Repository
}

\author{
Seok Yoon *, WanHyoung Cho, Changsoo Lee and Geon-Young Kim \\ Division of Radioactive Waste Disposal Research, Korea Atomic Energy Research Institute (KAERI), 989-111, \\ Daedeok-daero, Yuseong-gu, Daejeon 34057, Republic of Korea; cho0714@kaeri.re.kr (W.C.); \\ leecs@kaeri.re.kr (C.L.); kimgy@kaeri.re.kr (G.-Y.K.) \\ * Correspondence: busybeeyoon@kaist.ac.kr; Tel.: +82-42-868-2946
}

Received: 27 June 2018; Accepted: 24 August 2018; Published: 29 August 2018

\begin{abstract}
Engineered barrier system (EBS) has been proposed for the disposal of high-level waste (HLW). An EBS is composed of a disposal canister with spent fuel, a buffer material, backfill material, and a near field rock mass. The buffer material is especially essential to guarantee the safe disposal of HLW, and plays the very important role of protecting the waste and canister against any external mechanical impact. The buffer material should also possess high thermal conductivity, to release as much decay heat as possible from the spent fuel. Its thermal conductivity is a crucial property since it determines the temperature retained from the decay heat of the spent fuel. Many studies have investigated the thermal conductivity of bentonite buffer materials and many types of soils. However, there has been little research or overall evaluation of the thermal conductivity of Korean Ca-type bentonite buffer materials. This paper investigated and analyzed the thermal conductivity of Korean Ca-type bentonite buffer materials produced in Gyeongju, and compared the results with various characteristics of Na-type bentonites, such as MX80 and Kunigel. Additionally, this paper suggests various predictive models to predict the thermal conductivity of Korean bentonite buffer materials considering various influential independent variables, and compared these with results for MX80 and Kunigel.
\end{abstract}

Keywords: bentonite buffer material; Ca-type bentonite; thermal conductivity; predictive models

\section{Introduction}

Spent fuels from nuclear energy sources release decay heat and harmful radiation for extended periods, creating longstanding issues with high-level waste (HLW). Among the various types of disposal systems, deep geological repositories based on the concept of engineered barrier system (Figure 1), which safely isolates HLWs from human society using a surrounding buffer, backfill, and near-field rock, are preferred in most countries, owing to their safety and reliability [1,2]. In EBS system, canisters packed with spent fuel are sealed with buffer and gap materials. The buffer is an important component of the repository. By filling the void between the near-field rock and the canister it minimizes groundwater inflow from intact rock while protecting the disposed HLW from any mechanical impact. For this reason, buffers must possess low hydraulic conductivity, to minimize the inflow of water from surrounding rocks saturated with groundwater. Furthermore, the buffer plays an important role in dissipating decay heat, and for this reason buffers must have high thermal conductivity to release as much as decay heat as possible from the spent fuel $[3,4]$.

In order to satisfy these buffer material criteria, researches have been conducted to determine the most adequate candidate materials. The studies found that bentonite is the most suitable material $[5,6]$. 
Bentonite belongs to the smectite group, which contains large amounts of montmorillonite. Bentonite forms 2:1 layer platy structures, and consists of two silica tetrahedral layers and an aluminum hydroxide octahedral layer. Anions generated from the isomorphous substitution in the montmorillonite readily absorb cations $\left(\mathrm{Na}^{+}, \mathrm{Mg}^{2+}, \mathrm{Ca}^{2+}\right.$, etc. $)$ between the layers to become electrostatically neutral. Bentonite can be largely classified as Na-type bentonite or Ca-type bentonite depending on the exchangeable cations absorbed to become neutral. In Korea, Ca-type bentonite has been produced in the Gyeongju region by CLARIANT KOREA, and since Ca-type bentonite is known to satisfy the appropriate performance criteria, it can be considered one of the candidate buffer materials for HLW repository facilities in Korea [7]. Ca-type bentonite produced before 2015 in Korea is called KJ-I, and after 2015, it is known as KJ-II.

Many studies have been conducted to evaluate the complex thermal-hydro-mechanical (THM) behaviors of such buffers. The thermal conductivity of bentonite buffer materials considering the temperature limit is one of the most important design parameters to guarantee the entire safety performance in a disposal system [8]. However, even though many studies have investigated Na-type bentonite thermal conductivity [4,9-12], relatively few have investigated the thermal conductivity behavior models of the Ca-type bentonite produced in Korea. Therefore, this study measured the thermal conductivity of the Ca-type Korean bentonite and compared results with Na-type bentonite. Furthermore, this study suggested various predictive models for thermal conductivity considering dry density and degree of saturation, which are the main governing factors used to describe the thermal conductivity behavior of the buffer.

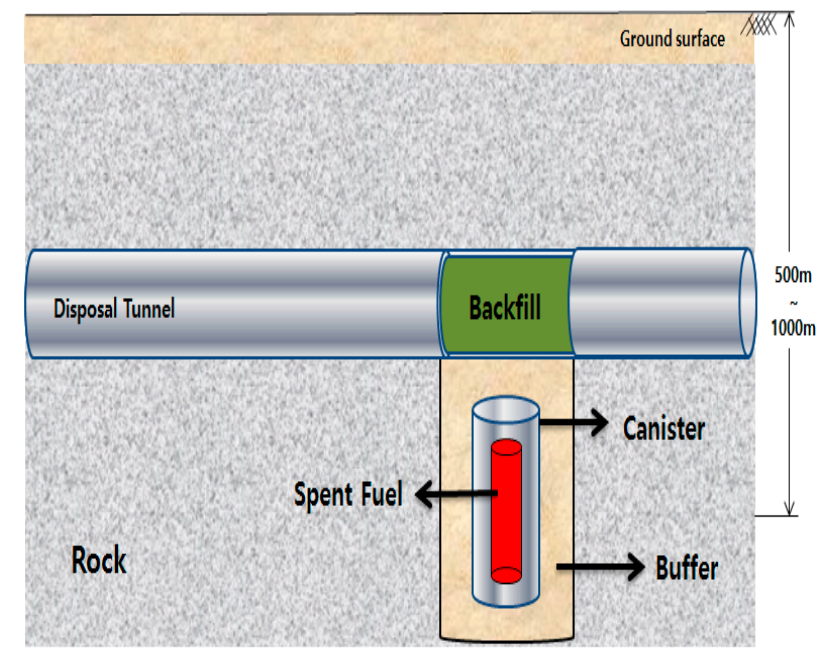

Figure 1. Engineered barrier system.

\section{Laboratory Experiment}

\subsection{Mineral Composition of Bentonite}

Ca-type bentonites (KJ-I and KJ-II) produced from Gyeongju contains montmorillonite (70\%), feldspar (29\%), and small amounts of quartz ( 1\%). Figure 2 shows XRD analysis results for KJ-I and KJ-II, and Table 1 presents a quantitative analysis of the thermal conductivity of the constitutive minerals. The quantitative analyses were conducted three times. The amount of montmorillonite was a little higher in KJ-I, but there was not a big difference in mineral composition between KJ-I and KJ-II.

Unlike the Ca-type bentonite in this study, for Na-type bentonite the percent of montmorillonite varies. According to the previous researches conducted by Villar [12] and Tang et al. [11], MX80, which is a very well-known commercial Na-type bentonite, contains montmorillonite (92\%) and quartz (3\%). Another Na-type bentonite considered a potential buffer material in Japan, called Kunigel, has a relatively smaller portion of montmorillonite. It mainly contains montmorillonite $(46 \sim 49 \%)$ and 
quartz (29 38\%) [3,11]. Table 2 shows the clay properties considering the Atterberg limit [13,14] Every bentonite is classified as $\mathrm{CH}$ with very high plasticity based on the unified soil classification system (USCS) [15]. On the whole, the Atterberg limit values of KJ-I and KJ-II were much higher than Na-type bentonites, such as MX-80 and Kunigel. It is thought that Na-type bentonite has higher compressibility and a little less tendency to be mechanically stable than Ca-type bentonite. Furthermore, MX80 showed the highest Atterberg limit, which means that MX80 has much more expansive characteristics.
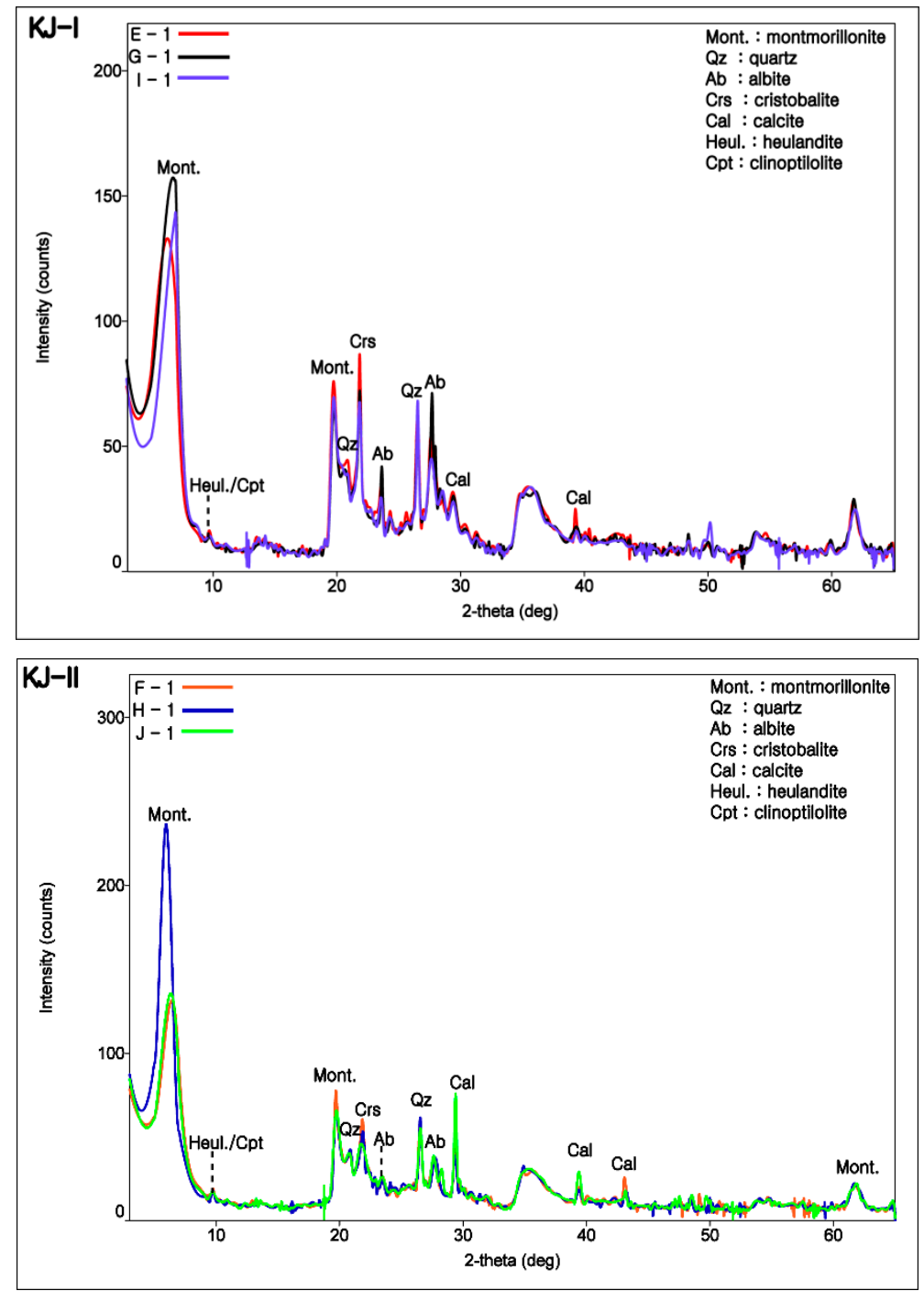

Figure 2. X-ray diffraction pattern of the KJ-I and KJ-II powders.

Table 1. Quantitative XRD analysis for mineral constituents of KJ-I and KJ-II powders.

\begin{tabular}{ccccccccc}
\hline Bentonite Type & \multicolumn{3}{c}{ KJ-I } & \multicolumn{4}{c}{ KJ-II } \\
\hline Sample No. & $\mathbf{1}$ & $\mathbf{2}$ & $\mathbf{3}$ & Avg. & $\mathbf{4}$ & $\mathbf{5}$ & $\mathbf{6}$ & Avg. \\
\hline Montmorillonite & 60.0 & 67.4 & 62.1 & 63.2 & 63.4 & 61.7 & 60.5 & 61.9 \\
Albite $(\lambda=1.96 \mathrm{~W} / \mathrm{mK})$ & 27.2 & 22.2 & 27.5 & 25.6 & 19.4 & 22.8 & 20.4 & 20.9 \\
Quartz $(\lambda=7.69 \mathrm{~W} / \mathrm{mK})$ & 5.0 & 4.8 & 5.0 & 4.9 & 5.8 & 4.9 & 5.3 & 5.3 \\
Cristobalite $(\lambda=6.15 \mathrm{~W} / \mathrm{mK})$ & 3.6 & 1.8 & 3.5 & 3.0 & 4.0 & 4.5 & 3.7 & 4.1 \\
Calcite $(\lambda=3.59 \mathrm{~W} / \mathrm{mK})$ & 2.4 & 2.0 & 2.0 & 2.1 & 4.3 & 3.3 & 6.8 & 4.8 \\
Heulandite $(\lambda=1.09 \mathrm{~W} / \mathrm{mK})$ & 1.8 & 1.7 & Miner & 1.8 & 3.0 & 2.7 & 3.3 & 3.0 \\
\hline
\end{tabular}


Table 2. Geotechnical properties of bentonites.

\begin{tabular}{cccccc}
\hline & Specific Gravity & Liquid Limit (\%) & Plastic Limit (\%) & Plastic Index (\%) & USCS \\
\hline KJ-I & 2.74 & 244.5 & 46.1 & 198.4 & $\mathrm{CH}$ \\
KJ-II & 2.71 & 146.7 & 28.4 & 118.3 & $\mathrm{CH}$ \\
MX-80 [11] & 2.76 & 520 & 42 & 478 & $\mathrm{CH}$ \\
Kunigel [11] & 2.79 & 415 & 32 & 383 & $\mathrm{CH}$ \\
\hline
\end{tabular}

\subsection{Equipment for Measuring Thermal Conductivity}

The thermal conductivity of the compacted bentonite buffer materials were measured using QTM-500 (Kyoto Electronics Manufacturing Company, Kyoto, Japan), based on the transient line source method [16]. In this approach, an impulse of thermal flow is supplied by hot wire into the specimen, and temperature rise is measured within a certain time. As the temperature rises, the thermal conductivity is measured using Equation (1):

$$
\lambda=\frac{Q}{4 \pi \Delta T} \ln \left(\frac{t_{2}}{t_{1}}\right)
$$

where $\lambda$ is the thermal conductivity $\left(\mathrm{W} \cdot \mathrm{m} \cdot \mathrm{K}^{-1}\right), Q$ is the heat capacity per unit length $\left(\mathrm{W} \cdot \mathrm{m}^{-1}\right), T$ is the temperature $(\mathrm{K})$, and $t$ is the time $(\mathrm{s})$. The bentonite powders were compressed using the floating die method, and the sample size was $100 \mathrm{~mm} \times 50 \mathrm{~mm} \times 20 \mathrm{~mm}$.

\section{Experimental Results}

\section{Thermal Conductivity}

It is known that the thermal conductivity of the compacted bentonite buffer materials mainly depends on the degree of saturation and dry density $[3,5,17,18]$. Thus, thermal conductivity of the KJ-II bentonite was measured with various water contents and dry densities. This paper collected 142 datasets for KJ-I [5,18], and 34 datasets for KJ-II was obtained using the QTM-500 equipment. Table 3 provides a summary of the statistical quantities used for the analysis, and Figure 3 depicts the thermal conductivity in proportion to dry density and degree of saturation. On the whole, the thermal conductivity of KJ-II was slightly higher than that of KJ-I because KJ-II has more minerals with high thermal conductivity, including quartz, cristobalite, and calcite, than KJ-I. TANG et al. [11] also explained that the thermal conductivity of the constitutive minerals can affect the total thermal conductivity of the bentonite buffer materials. In addition, the thermal conductivity of KJ-II was measured by drying path, while that of KJ-I was measured by wetting path. It is known that thermal conductivity is higher when measured by drying than by wetting [11,19]. However, there was no great difference in thermal conductivity values between KJ-I and KJ-II except for the low saturation. In comparison, the thermal conductivities of KJ-I and KJ-II were slightly higher than that of MX80 because of mineral composition and the high degree of saturation.

Table 3. Summary of descriptive statistical quantities.

\begin{tabular}{ccccccccc}
\hline & & N & Minimum & Maximum & Average & Standard Deviation & Skewness & Kurtosis \\
\hline \multirow{2}{*}{ KJ-I } & Dry density $\left(\mathrm{Mg} / \mathrm{m}^{3}\right)$ & \multirow{2}{*}{142} & 1.200 & 1.800 & 1.510 & 0.154 & -0.223 & 0.095 \\
& Degree of saturation $(\%)$ & & 1.000 & 0.469 & 0.244 & 0.159 & -0.022 \\
& Thermal conductivity $(\mathrm{W} /(\mathrm{m} \cdot \mathrm{K}))$ & & 0.301 & 1.445 & 0.722 & 0.248 & 0.686 & -0.203 \\
\hline \multirow{2}{*}{$\mathrm{KJ}-\mathrm{II}$} & Dry density $\left(\mathrm{Mg} / \mathrm{m}^{3}\right)$ & \multirow{2}{*}{34} & 1.572 & 1.803 & 1.693 & 0.068 & -0.024 & -0.963 \\
& Degree of saturation $(\%)$ & & 0.000 & 0.678 & 0.177 & 0.233 & 1.185 & -0.184 \\
& Thermal conductivity $(\mathrm{W} /(\mathrm{m} \cdot \mathrm{K}))$ & & 0.627 & 1.046 & 0.805 & 0.116 & 0.761 & -0.360 \\
\hline
\end{tabular}




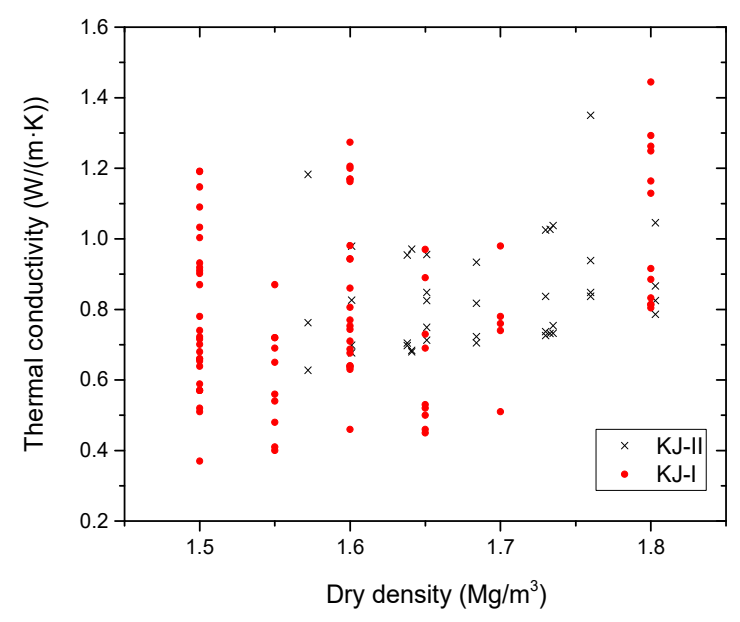

(a) Thermal conductivity vs. dry density

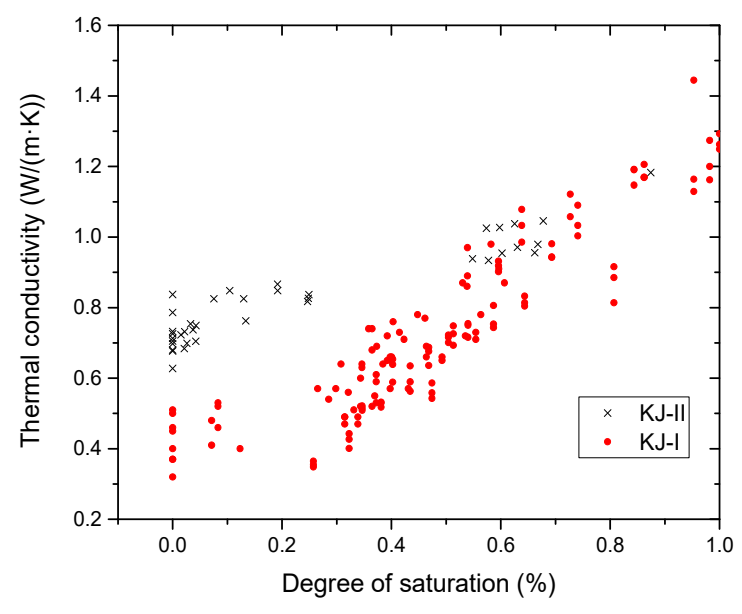

(b) Thermal conductivity vs. degree of saturation

Figure 3. Thermal conductivity variation $\mathrm{KJ}$ bentonites.

\section{Thermal Conductivity Models for KJ-I and KJ-II}

\subsection{Models with $1.6 \mathrm{Mg} / \mathrm{m}^{3}$ of Dry Density}

To satisfy the required functional criteria, the suggested dry density of compacted bentonite buffer for Korea disposal systems is more than $1.6 \mathrm{Mg} / \mathrm{m}^{3}$ [20]. Accordingly, the thermal conductivity model was derived for a bentonite buffer dry density of $1.6 \mathrm{~g} / \mathrm{cm}^{3}$. Since there were only three datasets for KJ-II, as shown in Table 4, both the KJ-I and the KJ-II datasets were used, making a total of 23. Many predictive models have been proposed to predict the thermal conductivity of compacted bentonite buffer materials, and this paper mainly used three models. To begin with, a linear regression analysis was applied. Equation (2) represents the linear regression model:

$$
\lambda=0.6683 S+0.4977
$$

Here, $\lambda$ is thermal conductivity $(\mathrm{W} /(\mathrm{m} \cdot \mathrm{K}))$, and $S$ means the degree of saturation. The $R^{2}$ value was around 0.77. Wilson et al. [21] and Lee et al. [22] also used the following empirical formula, which is well known to be adequate for predicting the thermal conductivity of compacted bentonite buffer materials:

$$
\lambda=\frac{A_{1}-A_{2}}{1+\exp \left(\left(S-S_{a v}\right) / B\right)}+A_{2}
$$


$A_{1}$ represents the value of $\lambda$ when $S=0, A_{2}$ means $\lambda$ when $S=1 . S_{a v}$ is the degree of saturation when the thermal conductivity is the average of the two extreme values, and $B$ is a fitting parameter. Furthermore, with the $A_{1}$ and $A_{2}$ values, thermal conductivity can also be predicted, as in Equation (4) [2]:

$$
\lambda=A_{1}{ }^{1-S} A_{2}{ }^{S}
$$

Figure 4 shows fitting curves, and Table 5 represents the summary of the predictive models and the fitting parameters, especially for Equations (3) and (4). The parameters for Equations (3) and (4) were derived using the curve fitting tool from the MATLAB program. This tool has a function for deriving the optimum equation that yields the highest $R^{2}$ value.

Table 4. Summary of descriptive statistical quantities for KJ-I and KJ-II with $1.6 \mathrm{Mg} / \mathrm{m}^{3}$ of dry density.

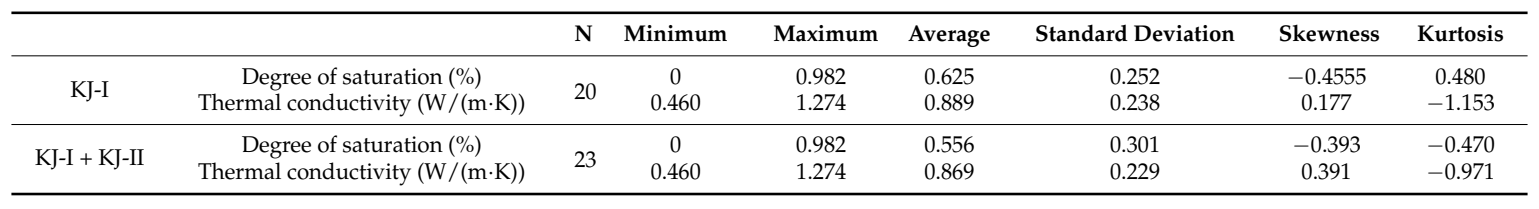

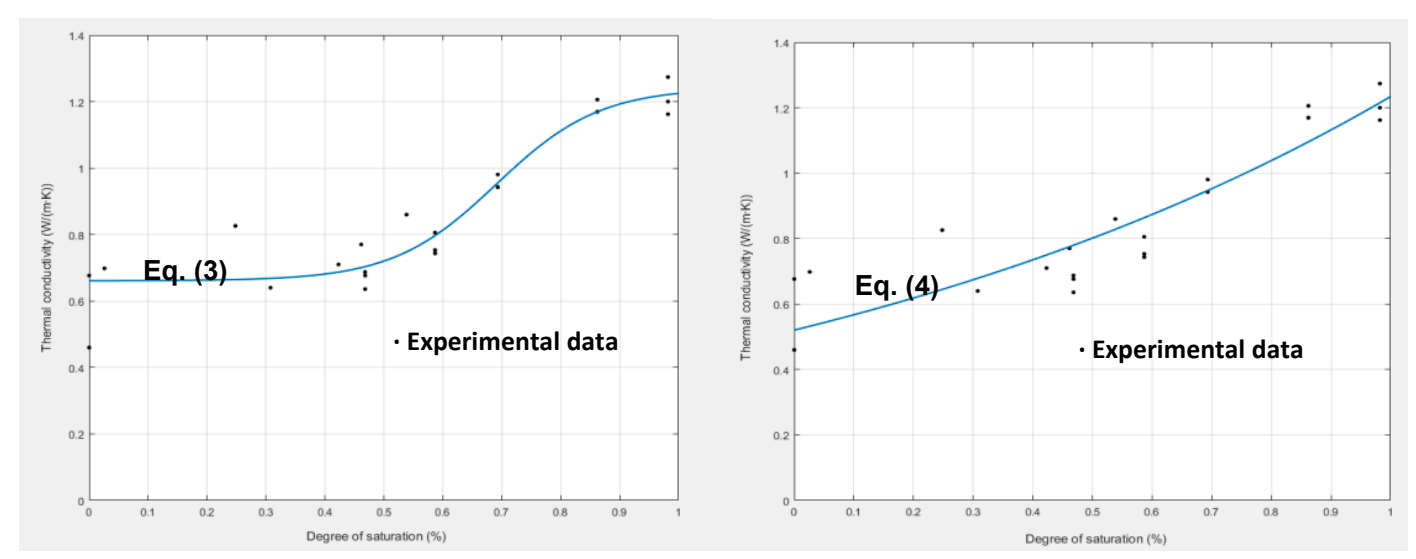

Figure 4. Fitting curves for Equations (3) and (4).

Table 5. Summary of predictive models.

\begin{tabular}{ccccccc}
\hline & \multicolumn{3}{c}{ Equation (3) } & \multicolumn{2}{c}{ Equation (4) } \\
\hline \multirow{2}{*}{ Parameters } & $A_{1}$ & $A_{2}$ & $B$ & $S_{a v}$ & $A_{1}$ & $A_{2}$ \\
& 0.6608 & 1.2410 & 0.0878 & 0.6906 & 0.5205 & 1.234 \\
\hline $\mathrm{R}^{2}$ & \multicolumn{4}{c}{0.9082} & \multicolumn{2}{c}{0.8329} \\
\hline
\end{tabular}

\subsection{Models Considering Various Dry Density and Degree of Saturation}

Since Equations (2)-(4) only consider the degree of saturation as an independent variable, a multiple regression analysis to predict thermal conductivity was conducted considering dry density and degree of saturation as independent variables. 176 datasets of KJ-I and KJ-II bentonites were used in the regression analysis, and Equation (5) was suggested:

$$
\lambda=0.641 \gamma_{d}+0.624 S-0.510
$$

Figure 5 shows the plot of predictive values from Equation (5) and measured values. Table 6 presents the results of the regression analyses, and the $\mathrm{R}^{2}$ value was 0.739 . Based on the $t$ analyses from Table 6 the P-value of the independent variable coefficients were lower than 0.05 , which means that the two independent variables can be used statistically to predict the dependent variables $[23,24]$. 
The variance inflation factor (VIF) was lower than 10, which means there was no multicollinearity among the independent variables [24]. Table 7 shows the ANOVA analysis. Since the P-values were less than 0.01 , there is a statistical significance between the independent and dependent variables ${ }^{30}$. A residual analysis was also conducted. The skewness was 0.210 , and kurtosis was $=-0.441$. Since the absolute value of skewness and kurtosis was less than 2, it can be assumed that the residuals are normally distributed [24,25]. Figure 6 draws the homoscedasticity plot of the residuals, and it can be assumed that the residuals followed the homoscedasticity condition since they do not exhibit a specific pattern [25].

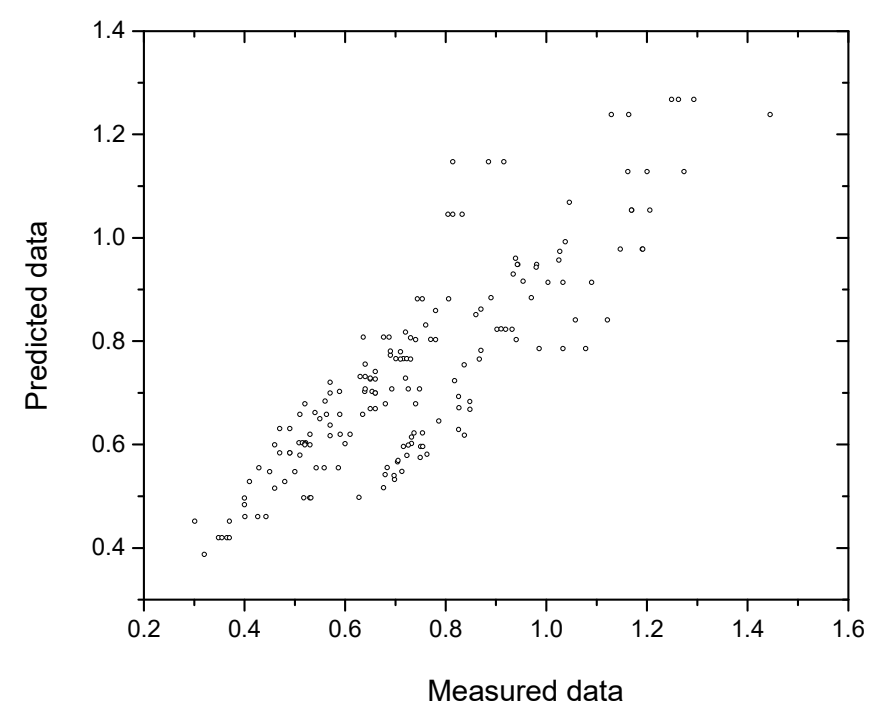

Figure 5. Thermal conductivity of predictive and measured values.

\section{Scatterplot}

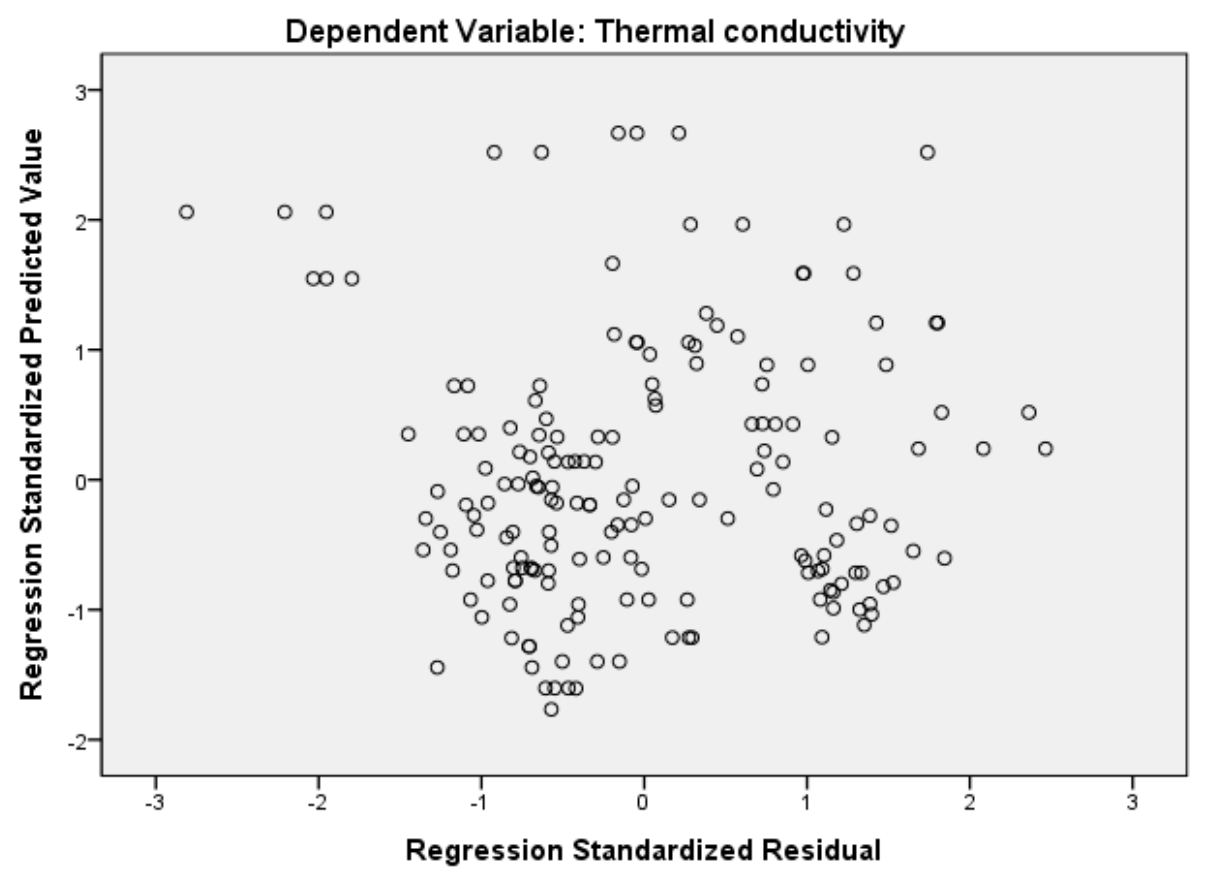

Figure 6. Homoscedasticity plot of residuals. 
Table 6. Results of multiple regression analysis model for KJ-I.

\begin{tabular}{cccccc}
\hline & $\boldsymbol{B}$ & Standard Error & $\boldsymbol{t}$ & $\boldsymbol{p}$-Value & $\boldsymbol{V} \boldsymbol{\text { IF }}$ \\
\hline Constant & -0.510 & 0.088 & -5.761 & $<0.01$ & \\
X1 (dry density) & 0.641 & 0.057 & 11.334 & $<0.01$ & 1.001 \\
X2 (degree of saturation) & 0.624 & 0.034 & 18.611 & $<0.01$ & 1.001 \\
$\mathrm{R}^{2}$ & 0.739 & & & & \\
adjR $^{2}$ & 0.736 & & & & \\
\hline
\end{tabular}

$B$ : non-standardized coefficient, $t: B /$ standard error, VIF: variance inflation factor.

Table 7. Results of ANOVA analysis.

\begin{tabular}{cccccc}
\hline & DF & SS & MS & F & $p$-Value \\
\hline Regression & 2 & 6.892 & 3.446 & 245.033 & $<0.01$ \\
Residuals & 173 & 2.433 & 0.014 & & \\
Total & 175 & 9.325 & & & \\
\hline
\end{tabular}

\subsection{Model Comparison with Na-Type Bentonite}

Many studies have also investigated the thermal conductivity of Na-type bentonites as mentioned in the introduction. Tang et al. [11] also measured the thermal conductivity of MX-80 and suggested various predictive models. Among them, the volume fraction of air and thermal conductivity showed good correlations. The empirical formula can be derived as Equation (6):

$$
\lambda=\alpha\left(V_{a} / V\right)+K_{\text {sat }}
$$

Here, $\alpha$ is the slope of the $K-V_{a} / V$ plot. $K_{s a t}$ is the thermal conductivity at the saturated condition. Equation (6) was also applied to predict thermal conductivity using the 176 datasets of the KJ-I and KJ-II bentonites. Once the dry density and the degree of saturation are obtained, the volume fraction of air can be easily obtained according to the basic geotechnical relation [26].

Table 8 summarizes the parameters from Equation (6) for the KJ, MX80 and Kunigel bentonites, and $\alpha$ and $K_{\text {sat }}$ were $=-2.05 / 1.22$ for KJ-I and $=-1.20 / 1.18$ for KJ-II. Thermal conductivity is inversely proportional to the air fraction because the thermal conductivity of air is much smaller than that of water and soil particles [5,22]. On average, the thermal conductivity of the Kunigel bentonite showed the highest thermal conductivity. Since Kunigel contains about ten times more quartz mineral than MX80, and 6-8 times more than KJ, it is thought that this is the reason Kunigel had a higher thermal conductivity than KJ and MX80. Therefore, it can be inferred that the thermal conductivity of the compacted bentonite buffer materials does not depend on the type of exchangeable cation, such as Ca-type or Na-type.

Table 8. Parameters from Equation (6).

\begin{tabular}{ccccccc}
\hline & \multicolumn{2}{c}{ KJ (Present Work) } & \multicolumn{2}{c}{ MX80 [11] } & \multicolumn{2}{c}{ Kunigel [11] } \\
\hline \multirow{2}{*}{ Parameters } & $\alpha$ & $K_{\text {sat }}$ & $\alpha$ & $K_{\text {sat }}$ & $\alpha$ & $K_{\text {sat }}$ \\
& -1.76 & 1.19 & -1.79 & 1.10 & -2.36 & 1.39 \\
\hline
\end{tabular}

\section{Conclusions}

This paper analyzed thermal conductivity results for Ca-type Korean bentonite buffer materials produced in the Gyeongju region, and suggested various predictive models with three influential independent variables: dry density, degree of saturation, and volume fraction of air. The main conclusions can be summarized as follows: 
First, 142 thermal conductivity datasets for the KJ-I bentonite were collected according to dry density and degree of saturation, 34 datasets for KJ-II bentonite were measured using the QTM-500 equipment which is based on the transient hot-wire method. The KJ-I and KJ-II bentonites are composed of more than $60 \%$ montmorillonite, and $5 \%$ quartz. The thermal conductivity of KJ-I and $\mathrm{KJ}-\mathrm{II}$ was proportional to dry density and degree of saturation. On average, the thermal conductivity of KJ-II was higher than that of KJ-I because KJ-II has a higher content of minerals with higher thermal conductivity, such as quartz, cristobalite, and calcite. Additionally, the thermal conductivity of KJ-II was measured by the drying path while KJ-I was measured by the wetting path. Compared to MX80, KJ-I and KJ-II had slightly higher thermal conductivities, and it is thought that this was mainly caused by the different mineral compositions of the $\mathrm{KJ}$ and MX80 bentonites.

The thermal conductivity estimation models for KJ-I and KJ-II were derived from this research. To satisfy the required functional criteria, the dry density of the buffer materials in Korean disposal systems was at least $1.6 \mathrm{Mg} / \mathrm{m}^{3}$. This paper used three main equations which are known to be adequate to predict the thermal conductivity of the compacted bentonite buffer materials when the dry density is $1.6 \mathrm{Mg} / \mathrm{m}^{3}$. In addition, this paper conducted a multiple regression analysis, and suggested a regression model for KJ-I and KJ-II which considered various dry densities and degrees of saturation as independent variables. The $\mathrm{R}^{2}$ value was 0.739 , and satisfied the statistical significance of the regression analyses. It is thought that the regression model proposed in this research can be used as an effective method to estimate the thermal conductivity of KJ-I and KJ-II. In order to compare with Na-type bentonites, such as MX80 and Kunigel, the empirical equation was applied with the volume fraction of air as the independent variable, since the volume fraction of air can be easily calculated using dry density and degree of saturation. Thermal conductivity is inversely proportional to the air fraction. The thermal conductivity of the Korean Ca-type bentonite was 10 15\% higher than MX80, but lower than Kunigel, which had different thermal conductivity values because of its mineral composition. It is thought that Kunigel contains about ten times more quartz than MX80, and 6-8 times more than $\mathrm{KJ}$.

The purpose of this paper was to investigate the thermal conductivity of Korean Ca-type bentonite, which can be considered one of the candidate buffer materials for safe HLW disposal in Korea. The predictive models of the Korean Ca-type bentonite suggested by this research can be applied in the design of such disposal systems, since they consider changes in saturation from the inflow of groundwater, and dry density from decay heat. The Na-type bentonite is known to have more swelling, but buffer materials are also required to have high thermal conductivity in order to release as much decay heat as possible from the spent fuel. It is thought that bentonite, which contains minerals with high thermal conductivity, will be adequate as a buffer material in terms of thermal properties. Furthermore, in the future, it will be necessary to determine optimum buffer materials which contain minerals with high thermal conductivity and swelling capacity.

Author Contributions: S.Y. and W.C. conducted experiment; C.L. and G.-Y.K. analyzed the data; and the authors made equal contribution and efforts on writing the manuscript.

Funding: This research was fundeded by the Nuclear Research and Development Program of the National Research Foundation of Korea (NRF-2017M2A8A5014857).

Conflicts of Interest: The authors declare no conflict of interest.

\section{References}

1. Cho, W.J.; Kwon, S. Effects of Variable Saturation on the Thermal Analysis of the Engineered Barrier System for a Nuclear Waste Repository. Nucl. Technol. 2012, 2, 245-256. [CrossRef]

2. Gens, A.; Sánchez, M.; Do, L.; Guimarães, N.; Aloson, E.E.; Lloret, A.; Olivella, S.; Villar, M.V.; Huertas, F. A full-scale in situ heating test for high-level nuclear waste disposal: Observation, analysis and interpretation. Geotechnique 2009, 59, 377-399. [CrossRef] 
3. Japan Nuclear Cycle Development Institute (JNC). H12 Project to Establish Technical Basis for HLW Disposal in Japan (Supporting Report 2); JNC TN1400-99-020; Japan Nuclear Cycle Development Institute: Ibaraki, Japan, 1999.

4. Ye, W.M.; Chen, Y.G.; Chen, B.; Wang, Q.; Wang, J. Advances on the knowledge of the buffer/backfill properties of heavily-compacted GMZ bentonite. Eng. Geol. 2010, 116, 12-20. [CrossRef]

5. Cho, W.J.; Kwon, S. An empirical model for the thermal conductivity of compacted bentonite and a bentonite-sand mixture. Heat Mass Transf. 2011, 47, 1385-1393. [CrossRef]

6. Hoffmann, C.; Alonso, E.E.; Romero, E. Hydro-mechanical behavior of bentonite pellet mixtures. Phys. Chem. Earth 2007, 32, 832-849. [CrossRef]

7. Lee, J.O.; Choi, H.J.; Kim, G.Y. Numerical simulation studies on predicting the peak temperature in the buffer of an HLW repository/Numerical simulation studies on predicting the peak temperature in the buffer of an HLW repository. Int. J. Heat Mass Trasnf. 2017, 115, 192-204. [CrossRef]

8. Zheng, L.; Rutqvist, J.; Birkholzer, J.T.; Liu, H.H. On the impact of temperature up to $200{ }^{\circ} \mathrm{C}$ in clay repositories with bentonite engineer barrier systems: A study with coupled thermal, hydrological, chemical, and mechanical modeling. Eng. Geol. 2015, 97, 278-295. [CrossRef]

9. Börgesson, L.; Chijimatsu, M.; Fujita, T.; Nguyen, T.S.; Rutqvist, J.; Jing, L. Thermo-hydro-mechanical characterization of a bentonite-based buffer material by laboratory tests and numerical back analyses. Int. J. Rock Mech. Min. Sci. 2001, 38, 95-104. [CrossRef]

10. Tang, A.M.; Cui, Y.J. Effects of mineralogy on thermo-hydro-mechanical parameters of MX 80 bentonite. Int. J. Rock Mech. Geotech. Eng. 2010, 2, 91-96.

11. Tang, A.M.; Cui, Y.J.; Le, T.T. A study on the thermal conductivity of compacted bentonites. Appl. Clay Sci. 2008, 41, 181-189. [CrossRef]

12. Villar, M.V. MX-80 Bentonite. Thermo-Hydro-Mechanical Characterization Performed at CIEMAT in the Context of the Prototype Project; Centro de Investigaciones Energeticas, Medioambientalesy Tecnologicas: Madrid, Spain, 2005.

13. Hrubesova, E.; Lunackova, B.; Brodzki, O. Comparison of liquid limit of soils resulted from Casagrande test and modificated cone penetrometor methodology. Procedia Eng. 2016, 142, 364-370. [CrossRef]

14. Andrade, F.A.; Al-Qureshi, H.A.; Hotza, D. Measuring the plasticity of clays: A review. Appl. Clay Sci. 2011, 51, 1-7. [CrossRef]

15. ASTM D2487/17-Standard Practice for Classification of Soils for Engineering Purpose (Unified Soil Classification System); ASTM International: West Conshohocken, PA, USA, 2017.

16. ASTM C1113/C1113M-09_Standard Test Method for Thermal Conductivity of Refractories by Hot Wire (Platinum Resistance Thermometer Technique); ASTM International: West Conshohocken, PA, USA, 2013.

17. Ballarini, E.; Graupner, B.; Bauer, S. Thermal-hydraulic-mechanical behavior of bentonite and sand-bentonite materials as seal for a nuclear waste repository: Numerical simulation of column experiments. Appl. Clay Sci. 2017, 135, 289-299. [CrossRef]

18. Lee, J.P.; Choi, J.W.; Choi, H.J.; Lee, M.S. Increasing of Thermal Conductivity from Mixing of Additive on a Domestic Compacted Bentonite Buffer. J. Nucl. Fuel Cycle Waste Technol. 2013, 11, 11-21. [CrossRef]

19. Farouki, O.T. Thermal Properties of Soils; Series on Rock and Soil Mechanics; Trans Tech Publications: Zürich, Switzerland, 1986.

20. Cho, W.J.; Kim, G.Y. Reconsideration of thermal criteria for Korean spent fuel repository. Ann. Nucl. Energy 2016, 88, 73-82. [CrossRef]

21. Wilson, J.; Savage, D.; Bond, A.; Watson, S.; Pusch, R.; Bennet, D. Bentonite: A Review of Key Properties, Process and Issues for Consideration in the UK Context; QRS-1378zG-1.1; Quintessa Limited: Oxfordshire, UK, 2011.

22. Lee, J.O.; Choi, H.; Lee, J.Y. Thermal conductivity of compacted bentonite as a buffer material for a high-level radioactive waste repository. Ann. Nucl. Energy 2016, 94, 848-855. [CrossRef]

23. Hair, J.F., Jr.; Black, W.C.; Babin, B.J.; Anderson, R.E. Multivariate Data Analysis, 7th ed.; Prentice-Hall: Upper Saddle River, NJ, USA, 2009.

24. Yoon, S.; Lee, S.R.; Kim, Y.T.; Go, G.H. Estimation of saturated hydraulic conductivity of Korean weathered granite soils using a regression analysis. Geomech. Eng. 2015, 9, 101-113. [CrossRef] 
25. Park, J.Y. A statistical Entrainment Growth Rate Estimation Model for Debris-Flow Runout Prediction. Master's Thesis, Korea Advanced Institute of Science and Technology, Daejeon, Korea, 2015; 84p.

26. Das, B.M. Principle of Geotechnical Engineering, 6th ed.; Nelson: Nelson, New Zealand, 2006.

(c)

(C) 2018 by the authors. Licensee MDPI, Basel, Switzerland. This article is an open access article distributed under the terms and conditions of the Creative Commons Attribution (CC BY) license (http://creativecommons.org/licenses/by/4.0/). 